\title{
Active Monitoring of Travelers Arriving from Ebola-Affected Countries - New York City, October 2014-April 2015
}

\begin{abstract}
Alexander J. Millman, MD ${ }^{1,2}$; Shadi Chamany, MD³; Seth Guthartz ${ }^{3}$; Sayone Thihalolipavan, MD³; Michael Porter, PhD³; Andrew Schroeder, MPA ${ }^{3}$;
\end{abstract} Neil M. Vora, MD ${ }^{3,4}$; Jay K. Varma, MD $^{3}$; David Starr, MIA ${ }^{3}$

The Ebola virus disease (Ebola) outbreak in West Africa has claimed approximately 11,300 lives (1), and the magnitude and course of the epidemic prompted many nonaffected countries to prepare for Ebola cases imported from affected countries. In October 2014, CDC and the Department of Homeland Security (DHS) implemented enhanced entry risk assessment and management at five U.S. airports: John F. Kennedy (JFK) International Airport in New York City (NYC), O'Hare International Airport in Chicago, Newark Liberty International Airport in New Jersey, Hartsfield-Jackson International Airport in Atlanta, and Dulles International Airport in Virginia (2). Enhanced entry risk assessment began at JFK on October 11, 2014, and at the remaining airports on October 16 (3). On October 21, DHS exercised its authority to direct all travelers flying into the United States from an Ebola-affected country to arrive at one of the five participating airports. At the time, the Ebola-affected countries included Guinea, Liberia, Mali, and Sierra Leone. On October 27, CDC issued updated guidance for monitoring persons with potential Ebola virus exposure (4), including recommending daily monitoring of such persons to ascertain the presence of fever or symptoms for a period of 21 days (the maximum incubation period of Ebola virus) after the last potential exposure; this was termed "active monitoring." CDC also recommended "direct active monitoring" of persons with a higher risk for Ebola virus exposure, including health care workers who had provided direct patient care in Ebola-affected countries. Direct active monitoring required direct observation of the person being monitored by the local health authority at least once daily (5). This report describes the operational structure of the NYC Department of Health and Mental Hygiene's (DOHMH) active monitoring program during its first 6 months (October 2014-April 2015) of operation. Data collected on persons who required direct active monitoring are not included in this report.

DOHMH began planning for the possible importation of an Ebola case in August 2014 and activated its Incident Command System on October 3, 2014, after the first importation of Ebola into the United States occurred in Texas (6). On October 23, a humanitarian aid worker who had recently returned from Guinea was hospitalized in NYC and received a diagnosis of Ebola (7). On October 25, DOHMH, having been informed that $\mathrm{CDC}$ would be issuing guidance on monitoring travelers on October 27, opened the Active Monitoring Call Center
(AMCC) to monitor personnel who had contact with the NYC patient or with laboratory specimens and medical waste originating from the patient. Active monitoring also was implemented for travelers who had been in an Ebola-affected country within the preceding 21 days. Almost all of these travelers were designated as at low (but not zero) risk for an Ebola virus exposure because they had been in countries with widespread Ebola virus transmission but had no known exposures (8).

DHS personnel at ports of entry collected information about travelers requiring active monitoring for Ebola, which was entered into a database and then transmitted to $\mathrm{DOHMH}$ through CDC's Epidemic Information Exchange (Epi-X), ${ }^{*}$ a secure notification system (3). Additional information could also be collected through other domestic public health investigations. Risk classification of travelers (i.e., high risk, some risk, low [but not zero] risk, or no identifiable risk) (4) was generally performed by CDC staff members at ports of entry and was included in the Epi-X notification.

DOHMH assigned a unique identification number to each traveler and sent an e-mail to the traveler with instructions for contacting the AMCC. DOHMH then assigned travelers who required active monitoring to AMCC phone operators, who made at least two call attempts to all available telephone numbers, including to telephones issued to incoming travelers by CDC. Operators asked travelers to report two separate temperature recordings from the previous 24 -hour period, any episodes of vomiting, diarrhea, or unexplained bleeding or bruising, and any plans for overnight travel outside of NYC. Any traveler who reported a temperature $\geq 100.0^{\circ} \mathrm{F}\left(37.8^{\circ} \mathrm{C}\right)$ or symptoms was referred to the DOHMH physician on call for Ebola monitoring for evaluation. Possible outcomes after referral included continuing to monitor the traveler per usual protocol, increasing the frequency of monitoring (with or without restriction of movement), or transporting the traveler to a health care facility for further evaluation.

AMCC operators documented all call attempts regardless of outcome. A daily report was generated for AMCC leadership review; the report indicated which travelers did not provide monitoring data for 2 calendar days, including monitoring data collected previously, if any, and which travelers had incorrect contact information. For those travelers who did not respond to multiple contact attempts over 2 days, AMCC leadership

\footnotetext{
* http://www.cdc.gov/24-7/savinglives/epi-x/index.html.
} 
decided to either make additional call attempts that evening, or refer the travelers' records to the NYC Police Department Missing Persons Squad to conduct a database search for additional contact information or the DOHMH Field Surveillance Unit to visit any addresses listed, including those of emergency contacts. Daily monitoring reports for the NYC Office of the Mayor and weekly reports for CDC also were generated (Figure).

During October 25, 2014-April 30, 2015, CDC referred 2,452 travelers to DOHMH for active monitoring. The number of travelers referred each day ranged from 1-106 (mean $=13$ travelers, standard deviation $[S D]=10)$. Travelers arrived from all the Ebola-affected countries, with $47.4 \%$ originating in Guinea. Among all travelers, $44.0 \%$ were female; the mean age was 39 years, and $28.3 \%$ were U.S. citizens. Only $57.7 \%$ reported feeling comfortable communicating in English for the purpose of active monitoring (Table 1). Overall, 2,407 (98.1\%) referred travelers required active monitoring. The 45 $(1.9 \%)$ travelers who did not require monitoring were either transiting to another jurisdiction or had errors in their itineraries. The number of travelers called by AMCC operators ranged from eight to 301 per day $($ mean $=192, S D=53)$.

Whereas some travelers were monitored for the full 21-day period, a traveler's monitoring period could be $<21$ days if, for example, the traveler spent time in another jurisdiction between leaving an Ebola-affected country and arriving in NYC. During October 25, 2014-April 30, 2015, monitoring data were successfully collected for $>75 \%$ of the traveler's monitoring period for $2,138(88.8 \%)$ travelers, for $50 \%-75 \%$ of the monitoring period for $100(4.2 \%)$ travelers, and for $<50 \%$ of the monitoring period for $61(2.5 \%)$ travelers. For 108 (4.5\%) travelers, no monitoring data were collected (Table 2). Successful collection of monitoring data for travelers requiring active monitoring improved over time. For example, during October 25, 2014 December 31, 2014, data were successfully collected for $>75 \%$ of the travelers' monitoring period for 556 of 796 (69.8\%) travelers compared with 1,582 of $1,611(98.2 \%)$ travelers during January 1, 2015-April 30, 2015 ( $\mathrm{p}<0.01)$. Among the 2,299 (94\%) travelers reached for monitoring, 785 (34.1\%) left NYC during their monitoring period, including travelers who left the country or were transferred to another local health authority to continue active monitoring.

Approximately $98 \%$ of monitored travelers reported no fever or symptoms. Twenty-six (1.1\%) reported fever only; $27(1.2 \%)$ reported symptoms including diarrhea, vomiting or unexplained bleeding or bruising but no fever, and one $(0.04 \%)$ reported fever and symptoms. All travelers reporting

FIGURE. Flowchart showing protocol for active monitoring of travelers arriving from Ebola-affected countries - New York City, October 2014-April 2015

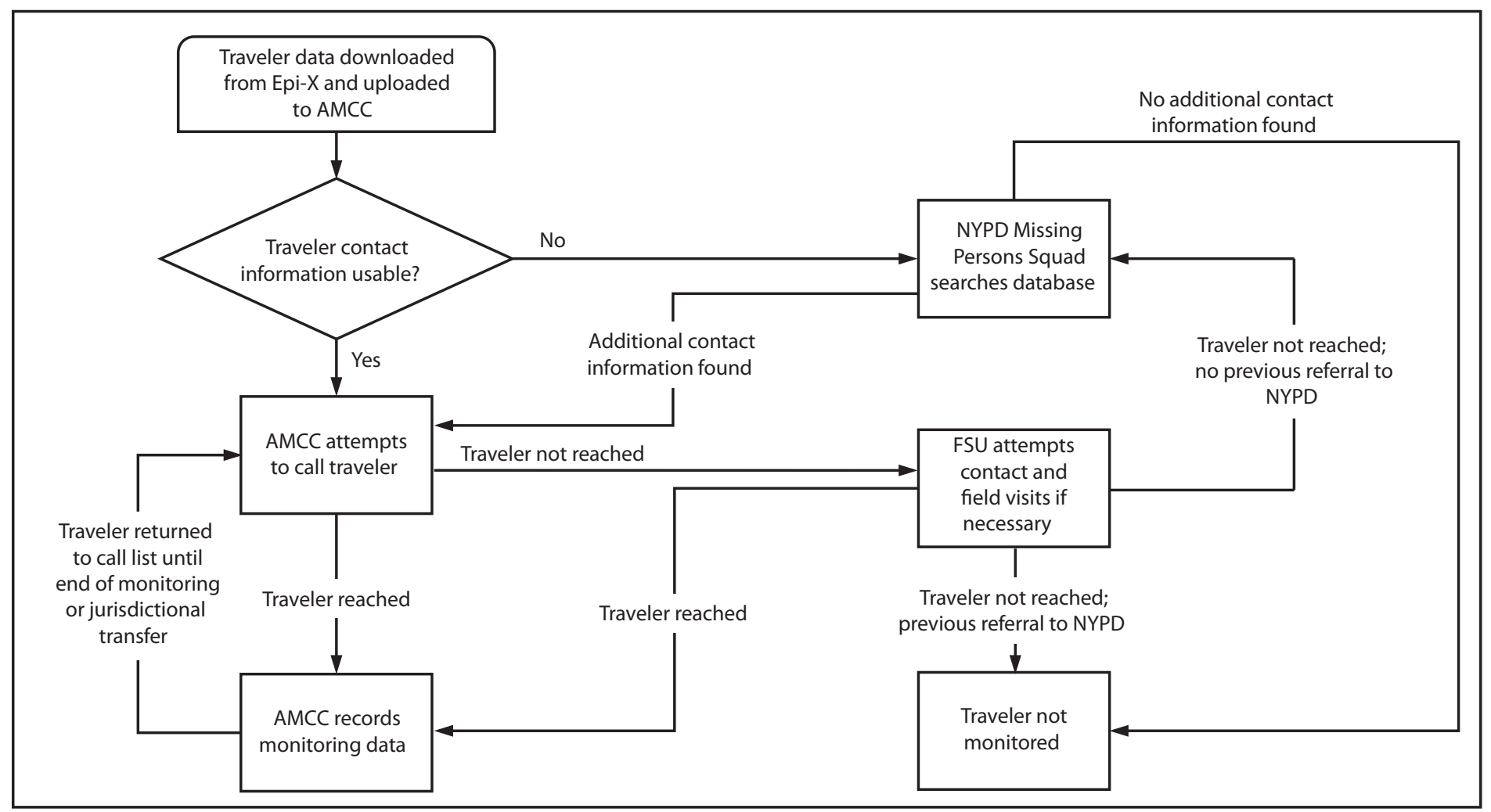

Abbreviations: $\mathrm{AMCC}=$ Active Monitoring Call Center; Epi- $\mathrm{X}=\mathrm{CDC}$ 's Epidemic Information Exchange; $\mathrm{FSU}=$ Field Surveillance Unit; $\mathrm{NYPD}=\mathrm{New}$ York City Police Department. 
TABLE 1. Characteristics of travelers arriving from Ebola-affected countries who were referred to the Department of Health and Mental Hygiene for active monitoring - New York City, October 25, 2014 April 30, 2015

\begin{tabular}{|c|c|}
\hline Characteristic & No. (\%) \\
\hline Travelers referred for active monitoring* & $2,452(100.0)$ \\
\hline \multicolumn{2}{|l|}{ Ebola-affected country visited } \\
\hline Guinea & $1,162(47.4)$ \\
\hline Liberia & $546(22.3)$ \\
\hline Sierra Leone & $339(13.8)$ \\
\hline Mali $^{\dagger}$ & $264(10.8)$ \\
\hline More than one country & $88(3.6)$ \\
\hline Unknown & $53(2.1)$ \\
\hline \multicolumn{2}{|l|}{ Sex } \\
\hline Male & $1,371(56.0)$ \\
\hline Female & $1,081(44.0)$ \\
\hline \multicolumn{2}{|l|}{ Citizenship } \\
\hline Non-United States $§$ & $1,371(56.0)$ \\
\hline United States & $695(28.3)$ \\
\hline Unknown & $386(15.7)$ \\
\hline \multicolumn{2}{|l|}{ Comfortable being monitored in English" } \\
\hline Yes & $1,414(57.7)$ \\
\hline No & $643(26.2)$ \\
\hline Unknown & $395(16.1)$ \\
\hline \multicolumn{2}{|c|}{$\begin{array}{l}\text { * A mean of } 13(\text { range }=1-106) \text { travelers were referred each day (standard } \\
\text { deviation }[S D]=10) . \text { Mean age of travelers = } 39 \text { years }(S D=16 \text { years); } \\
\text { range }=3-86 \text { years. } \\
+ \text { Travelers from Mali were monitored from November } 17,2014 \text { to January } 6,2015 . \\
\text { § Travelers' passports were from } 67 \text { countries and the United Nations. } \\
\text { "T Travelers who responded to an optional language preference question listed } \\
\text { sign language and eight other languages (Bombara, Chinese, Creole, French, } \\
\text { Fulani, Mandinga, and Pular). The Active Monitoring Call Center staff included } \\
\text { bilingual personnel to facilitate communication with persons with non-English } \\
\text { language preferences. }\end{array}$} \\
\hline
\end{tabular}

fever or symptoms were evaluated by the DOHMH physician on-call for Ebola monitoring to assess the evolution of illness and provide recommendations for any additional steps to take while the traveler remained ill. No cases of Ebola were detected among travelers reporting fever or symptoms during their monitoring period.

\section{Discussion}

The design and implementation of the Ebola active monitoring program by DOHMH required substantial resources. Although preparation for an imported Ebola case was under way in NYC since August 2014, the recommendation to actively monitor all travelers from Ebola-affected countries was not anticipated, and the program was established with little advance planning. The active monitoring program relied largely on existing funding, personnel, and technology, much of which was immediately available only because of continuous federal investment toward strengthening local public health capacity and public health emergency preparedness. Enhanced entry risk assessment and active monitoring for Ebola were new processes for CDC and local health authorities, and in the early stages of the national rollout, challenges
TABLE 2. Monitoring results for travelers arriving from Ebola-affected countries who were referred to the Department of Health and Mental Hygiene for active monitoring - New York City, October 25, 2014April 30, 2015

\begin{tabular}{|c|c|}
\hline Monitoring result & No. (\%) \\
\hline Travelers referred for active monitoring & $2,452(100.0)$ \\
\hline Travelers requiring active monitoring & $2,407(98.1)$ \\
\hline Active monitoring not required* & $45(1.9)$ \\
\hline \multicolumn{2}{|l|}{ Completeness of monitoring data collected for travelers } \\
\hline Monitoring data collected for $>75 \%$ of monitoring period ${ }^{\dagger}$ & $2,138(88.8)$ \\
\hline Monitoring data collected for $50 \%-75 \%$ of monitoring period & $100(4.2)$ \\
\hline for $<50 \%$ of monitoring period & $61(2.5)$ \\
\hline No monitoring data collected $\$$ & $108(4.5)$ \\
\hline \multicolumn{2}{|l|}{ Travelers' jurisdictional transfer and symptom dataף } \\
\hline Transferred out of NYC at any point during monitoring period & $785(34.1)$ \\
\hline Reported temperature $\geq 100.0^{\circ} \mathrm{F}$ & $26(1.1)$ \\
\hline Reported symptom(s)** & $27(1.2)$ \\
\hline Reported temperature $\geq 100.0^{\circ} \mathrm{F}$ and symptom $(\mathrm{s})^{* *}$ & $1(0.04)$ \\
\hline \multicolumn{2}{|c|}{$\begin{array}{l}\text { * Includes travelers transferred }>21 \text { days after departure date from an Ebola- } \\
\text { affected country, travelers who did not travel to the Ebola-affected countries } \\
\text { but had been referred because of an itinerary error, and travelers found to } \\
\text { be in other jurisdictions. }\end{array}$} \\
\hline \multicolumn{2}{|c|}{$\begin{array}{l}+ \text { Travelers monitored }>75 \% \text { of the time increased from } 556 \text { of } 796(69.8 \%) \\
\text { travelers during October } 25,2014 \text {-December } 31,2014 \text {, to } 1,582 \text { of } 1,611 \\
(98.2 \%) \text { travelers during January } 1,2015-\text { April } 30,2015 \text { ( }(\mathrm{p}<0.01) \text {. }\end{array}$} \\
\hline \multicolumn{2}{|c|}{$\begin{array}{l}\S \text { Travelers not monitored decreased from } 98 \text { during October } 25,2014- \\
\text { December } 31,2014 \text { to } 10 \text { during January } 1,2015 \text {-April 30, } 2015 \text {. }\end{array}$} \\
\hline \multicolumn{2}{|c|}{ 9 Percentages based on 2,299 travelers reached for monitoring. } \\
\hline
\end{tabular}

included poor data quality, lack of standard procedures for active monitoring of travelers as they moved between jurisdictions, and lack of standard methods of communication among local health authorities.

Despite the challenges, DOHMH created a robust system that benefited from continuous quality improvement as inefficiencies were assessed and addressed over time. Database software was updated to improve workflow operations, the flexibility of the information technology system, and report generation, which enhanced the coordination of monitoring activities. Epi-X data quality improved, especially with the accuracy of contact numbers following the provision of CDC-issued telephones to arriving travelers. As the program developed, staffing of the AMCC was able to transition to temporary workers, thus permitting DOHMH personnel to return to their regular duties. These improvements reduced reliance on DOHMH resources, and enabled the system to accommodate unexpected additions of up to 106 new travelers in a single day while continuing to conduct monitoring of an average of 192 travelers each day.

At present, CDC no longer recommends active monitoring of returning travelers returning from Mali, Liberia, Sierra Leone, or Guinea unless there is an identified potential Ebola virus exposure (9). DOHMH ended its active monitoring program on December 29, 2015. Maintaining the active monitoring program for the duration of the Ebola epidemic in West Africa required sustained effort and resources drawn 


\section{Summary}

What is already known on this topic?

The Ebola virus disease (Ebola) outbreak in West Africa prompted many nonaffected countries to prepare for possible importation of Ebola cases. State and local health departments in the United States developed programs to implement active monitoring of returning travelers from Ebola-affected countries.

What is added by this report?

During October 25, 2014-April 30, 2015, CDC referred 2,452 travelers to the New York City Department of Health and Mental Hygiene's (DOHMH's) active monitoring program. A total of $2,407(98.1 \%)$ of referred travelers required active monitoring; no cases of Ebola were detected.

What are the implications for public health practice?

The DOHMH's active monitoring program was successful in monitoring travelers returning from Ebola-affected countries; however, maintenance of the active monitoring program required sustained effort and resources drawn from core public health functions. Public health authorities should continue to work together and identify best practices to enhance information sharing and minimize duplication of efforts for future public health emergencies.

from core public health functions. Public health authorities should continue to work together and identify best practices to enhance information sharing and minimize unnecessary duplication of efforts for future public health emergencies.

\section{Acknowledgments}

Persons who underwent active monitoring; DOHMH Ebola Incident Command; DOHMH Quarantine and Monitoring (Countermeasures) Branch; DOHMH Surveillance and Epidemiology Branch; Ebola Active Monitoring Call Center staff members; NYC Police Department Missing Persons Squad.
${ }^{1}$ Epidemic Intelligence Service, CDC; ${ }^{2}$ Influenza Division, National Center for Immunization and Respiratory Diseases, CDC; ${ }^{3} \mathrm{New}$ York City Department of Health and Mental Hygiene; ${ }^{4}$ Division of State and Local Readiness, Office of Public Health Preparedness and Response, CDC.

Corresponding author: David Starr, dstarr@health.nyc.gov, 347-396-2706.

\section{References}

1. CDC. Ebola (Ebola virus disease). 2014 Ebola outbreak in West Africa. Atlanta, GA: US Department of Health and Human Services, CDC; 2014. http://www.cdc.gov/vhf/ebola/outbreaks/2014-west-africa/casecounts.html.

2. Department of Homeland Security. DHS's coordinated response to Ebola. Washington, DC: Department of Homeland Security; 2016. http://www. dhs.gov/ebola-response.

3. Brown CM, Aranas AE, Benenson GA, et al. Airport exit and entry screening for Ebola-August-November 10, 2014. MMWR Morb Mortal Wkly Rep 2014;63:1163-7.

4. CDC. Interim US guidance for monitoring and movement of persons with potential Ebola virus disease. Atlanta, GA: US Department of Health and Human Resources, CDC; 2015. http://www.cdc.gov/vhf/ebola/ exposure/monitoring-and-movement-of-persons-with-exposure.html.

5. Stehling-Ariza T, Fisher E, Vagi S, et al. Monitoring of persons with risk for exposure to Ebola virus disease-United States, November 3, 2014 March 8, 2015. MMWR Morb Mortal Wkly Rep 2015;64:685-9.

6. Chevalier MS, Chung W, Smith J, et al. Ebola virus disease cluster in the United States-Dallas County, Texas, 2014. MMWR Morb Mortal Wkly Rep 2014;63:1087-8.

7. Yacisin K, Balter S, Fine A, et al. Ebola virus disease in a humanitarian aid worker-New York City, October 2014. MMWR Morb Mortal Wkly Rep 2015;64:321-3.

8. CDC. Epidemiologic risk factors to consider when evaluating a person for exposure to Ebola virus. Atlanta, GA: US Department of Health and Human Resources, CDC; 2015. http://www.cdc.gov/vhf/ebola/exposure/ risk-factors-when-evaluating-person-for-exposure.html.

9. CDC. Questions and answers about CDC's Ebola monitoring \& movement guidance. Atlanta, GA: US Department of Health and Human Resources, CDC; 2015. http://www.cdc.gov/vhf/ebola/exposure/qasmonitoring-and-movement-guidance.html. 